\title{
CORROSION RESISTANCE OF SELECTED RAIL VEHICLES COMPONENTS TREATED BY THERMAL SPRAYING
}

\author{
Marek VOSTŘÁK ${ }^{1}$, Petra ŠULCOVÁ ${ }^{2}$, Jana NAĎOVÁ ${ }^{3}$ \\ Research and Testing Institute Plzeň, Plzeň, Czech Republic, EU, \\ 1votrak@vzuplzen.cz, ${ }^{2}$ sulcova@vzuplzen.cz, ${ }^{3}$ nadova@vzuplzen.cz
}

https://doi.org/10.37904/metal.2021.4208

\begin{abstract}
The trend to use modern materials and technologies in the development and construction of rail vehicles leads to testing new suitable alternatives for surface treatment of strain parts. Within the research project, suitable thermally sprayed coatings as alternatives for former surface treatment of selected components of rail vehicles are tested. The aim is to increase the functionality and service life of these parts. One of the key properties of these coatings has to be resistance against corrosion in the salt environment, as they need to protect the part for the whole life span in climatic conditions. In this study, possible coatings and the technology of their application are chosen for two components. These components are treated and tested in salt fog for 1000 hours along with parts treated by conventional surface treatment. The potential of the coatings for protecting the parts is analyzed. Based on the results, a suitable coating for the component will be selected.
\end{abstract}

Keywords: Thermal spraying, HVOF, APS, TWAS, coating, rail vehicles

\section{INTRODUCTION}

This work is a part of the project "Increasing of resistance of rail vehicle components by the means of modern thermal spraying technologies". The goal of the project is to find suitable alternatives for surface protection of components of rail vehicles for enhancing their life span ideally for the life span of entire vehicles which can be more than 40 years. There are more types of parts with different demands of surface properties, some are exposed only to outer climatic conditions and thus need protection against corrosion in a wet and salt environment and basic protections against abrasion. Other parts, for example in vehicle chassis, additionally need very high resistance against abrasion and/or suitable friction properties. These properties are achievable through thermal spraying technologies but there are several possible methods, as well as an almost unlimited number of materials suitable for the application of surface layers. To correctly choose the suitable coating layer, it is necessary to know the application of the part, the method of loading and types of acting stresses, the working environment, and the expected lifespan of the part. $[1,2,3]$.

Thermal spraying is a general term for forming metallic or non-metallic coatings with a thickness usually greater than $40 \mu \mathrm{m}$. The filler material (in the form of powder, wire, or rods) is partially melted using a heat source. It can be an electric arc, plasma, or flame. The heated and molten particles are accelerated towards the surface either by process gases or by atomizing nozzles. Due to the high kinetic energy, the particles are anchored on a roughened surface. This creates a bond with the surface of the substrate and the particles form a so-called lamellar structure $[1,2,3,4]$.

Some examples of possible applications of thermally sprayed coatings on rail vehicles components have been published in a previous study [5]. In this work, two components are selected with high demand on corrosion behavior. The suitable coatings for these components are selected and the goal is to assess their potential for protection against corrosion in a salt environment. 


\section{EXPERIMENTAL METHODS}

\subsection{Thermal spraying}

In this work, two components for rail vehicles are selected for testing. The first one is "The Pivot". This component has high demands on corrosion resistance, hardness, and resistance against abrasion. But it is a simple component, the functional part is rotary symmetrical. Based on requirements, suitable coatings are superalloys or carbide-based coatings. The chosen coatings were NiCrBSi (FST 771.33) by Flame spaying (FS) - this is a cheaper variation with lover coating quality - (Figure 1a), the HVOF (High-Velocity Oxygen Fuel) sprayed WC-CoCr (Woka 3652) coating - (Figure 1b) and HVOF sprayed CrC-NiCr coating (Amperit 588.074) - (Figure 1c). The HVOF technology offers superior quality coatings with minimum pores. The coating on this component would be machined for real application, therefore the tested parts were prepared accordingly. Figure 1 also shows the typical microstructure of these coatings.

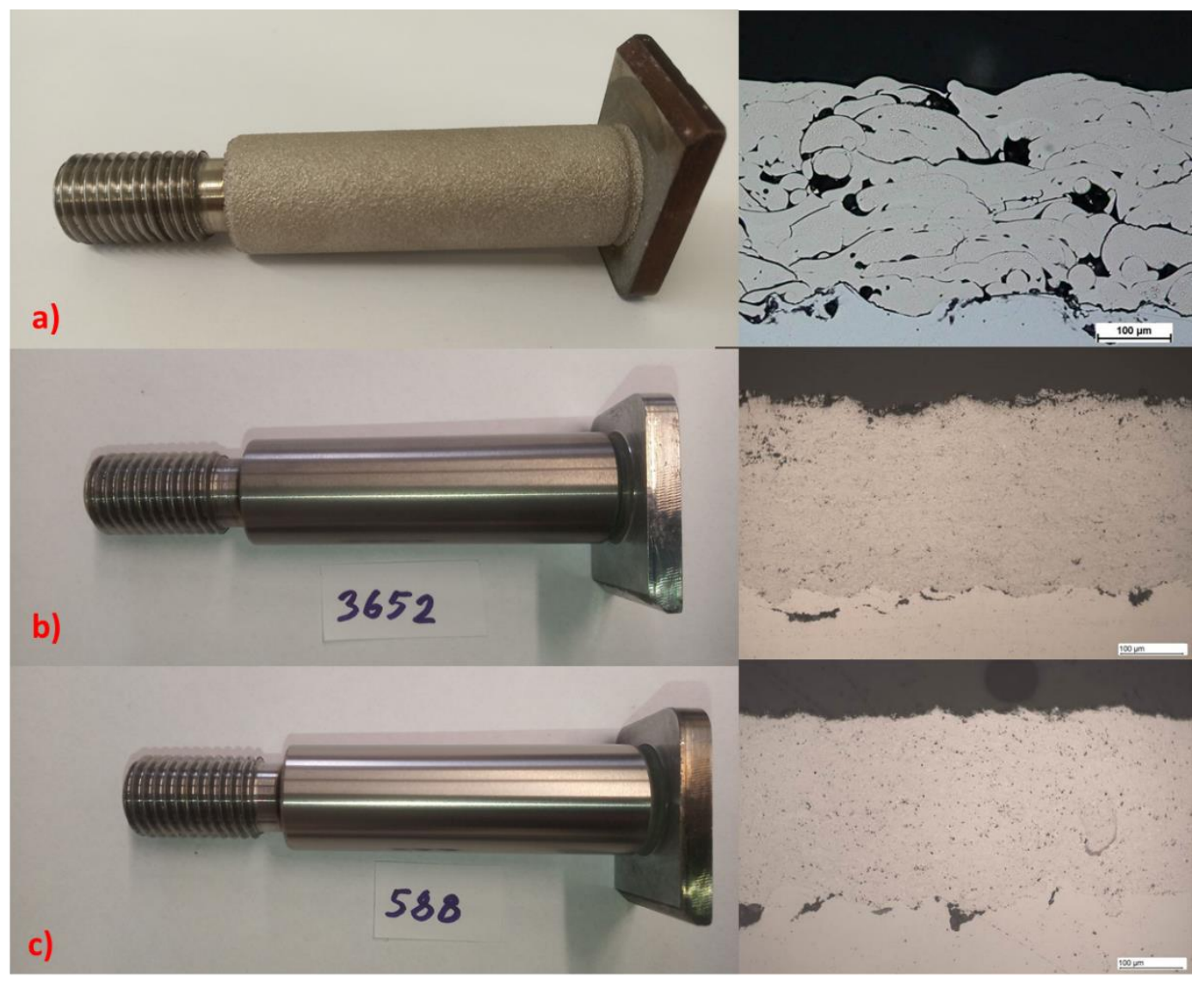

Figure 1 The component "Pivot" treated by thermal spraying;

a) Flame sprayed NiCrBSi (as-sprayed surface),

b) HVOF sprayed WC-CoCr; c) HVOF sprayed CrC-NiCr (machined surface).

The second component is "Roll holder“. This component has high demands on friction properties, along with the component "Pivot"and the third component they make the functional part. The functional surface of this component is geometrically more complicated, and therefore the robotic spraying would be quite expensive. For this reason, the technology TWAS (Twin Wire Arc Spraying) was selected. This technology enables handoperated spying and therefore is more suitable for these components. Drawbacks lower quality of coatings. Based on friction requirements, the Mo coating (99\% Mo] or the CuAl coating is considered. The sprayed component along with the typical microstructure of these coating is presented in (Figure 2). 


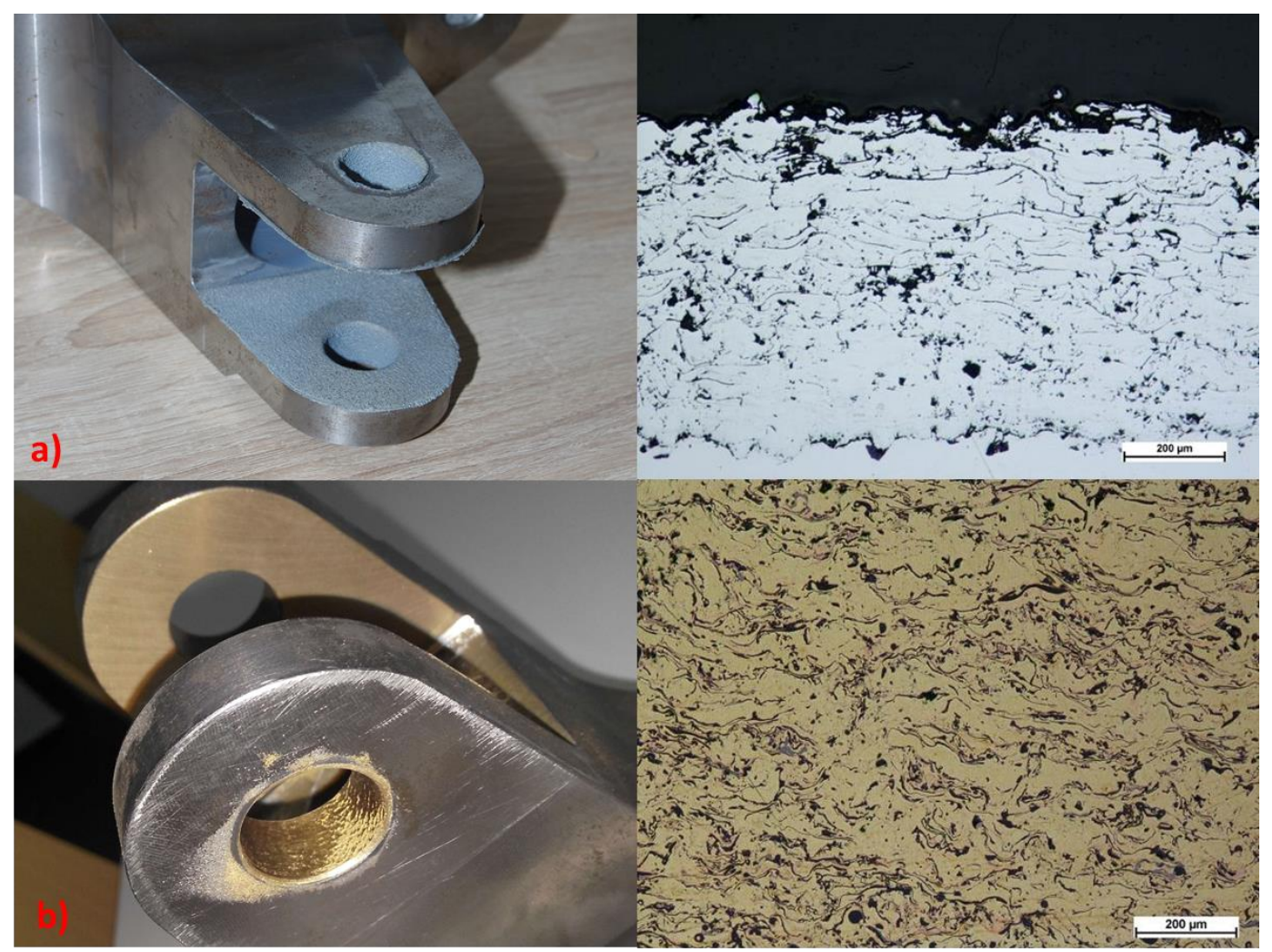

Figure 2 The component "Roll holder" a) TWAS sprayed Mo coating (as-sprayed)

b) TWAS sprayed CuAl coating (machined).

\subsection{Corrosion tests}

Salt spray testing is generally suitable as a corrosion protection test and for relatively rapid detection of pore and defect contents in inorganic and organic coatings and is a frequently used method. In this test, the ability of the coatings to prevent the passage of an aggressive environment through the coating to the substrate is tested. The principle of the test consists of exposing the test surface to an aggressive environment in the form of salt spray, which is created in a closed chamber by a special nozzle. The basis for the formation of a fine aerosol is saline $\mathrm{NaCl}$ solution. The test is performed in accordance with the standard ČSN EN ISO 9227 (Corrosion tests in artificial atmospheres - salt spray tests). The parameters of the conducted test are: concertation of salt spray $5 \pm 1 \%$; $\mathrm{pH} 6,5-7,2$; temperature $35 \pm 2^{\circ} \mathrm{C}$; duration of test $1000 \mathrm{~h}$.

\section{RESULTS AND DISCUSSION}

\subsection{The component "Pivot"}

The tested parts after the $1000 \mathrm{~h}$ salt spray corrosion test are presented in (Figure 3). For comparison, the original part is added to the test. The whole surface of this part is treated by COATING GEOMET $321 \mathrm{~A}+\mathrm{VL}$ ISO 10683. For the first view, it can be seen that the Geomet coating has withstood the corrosion test. The HVOF sprayed WC-CoCr and $\mathrm{CrC}-\mathrm{NiCr}$ coatings also show no sign of degradation on the first inspection. The FS sprayed NiCrBSi coating shows very high degradation. The microstructure of the coatings after the salt spray test is depicted in (Figure 4). From this detail it can be seen that the best performance for corrosion protection provides the WC-CoCr coating, the CrC-NiCr coating shows some beginning of the corrosion on the interface with the substrate. The FS coating is shows very poor behavior in this test due to the high porosity of this coating. 


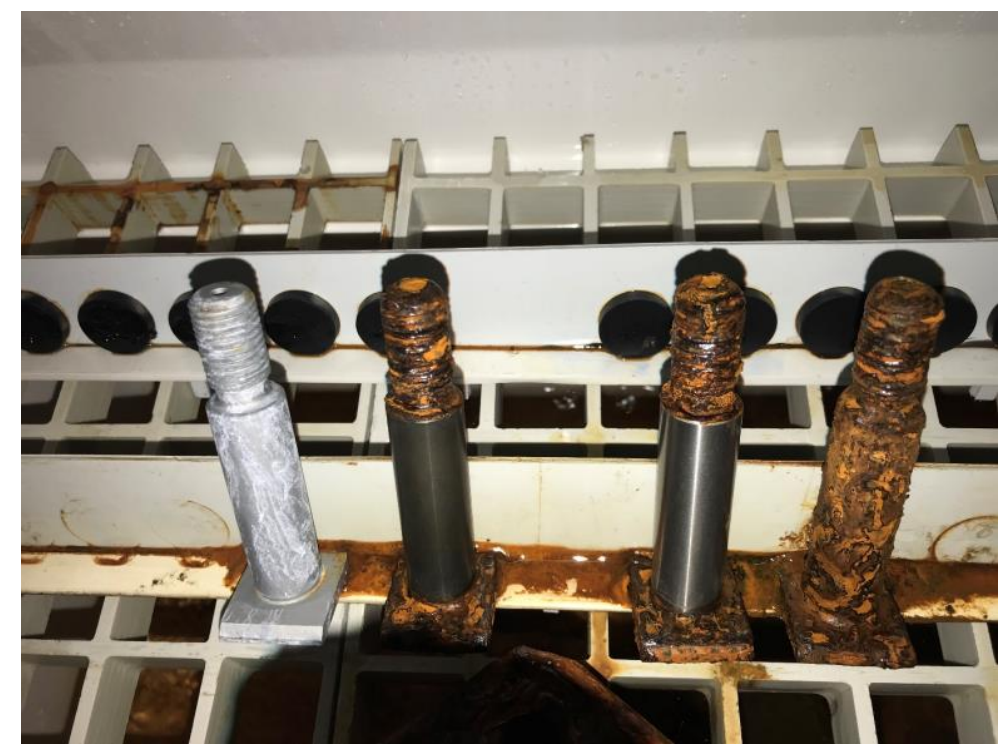

Figure 3 The tested parts "Pivot" after $1000 \mathrm{~h}$ salt spray test. From left to right:

Original part - Geomet; WC-CoCr (Woka 3652); CrC-NiCr (Amperit 588.074), NiCrBSi (FST 771.33)

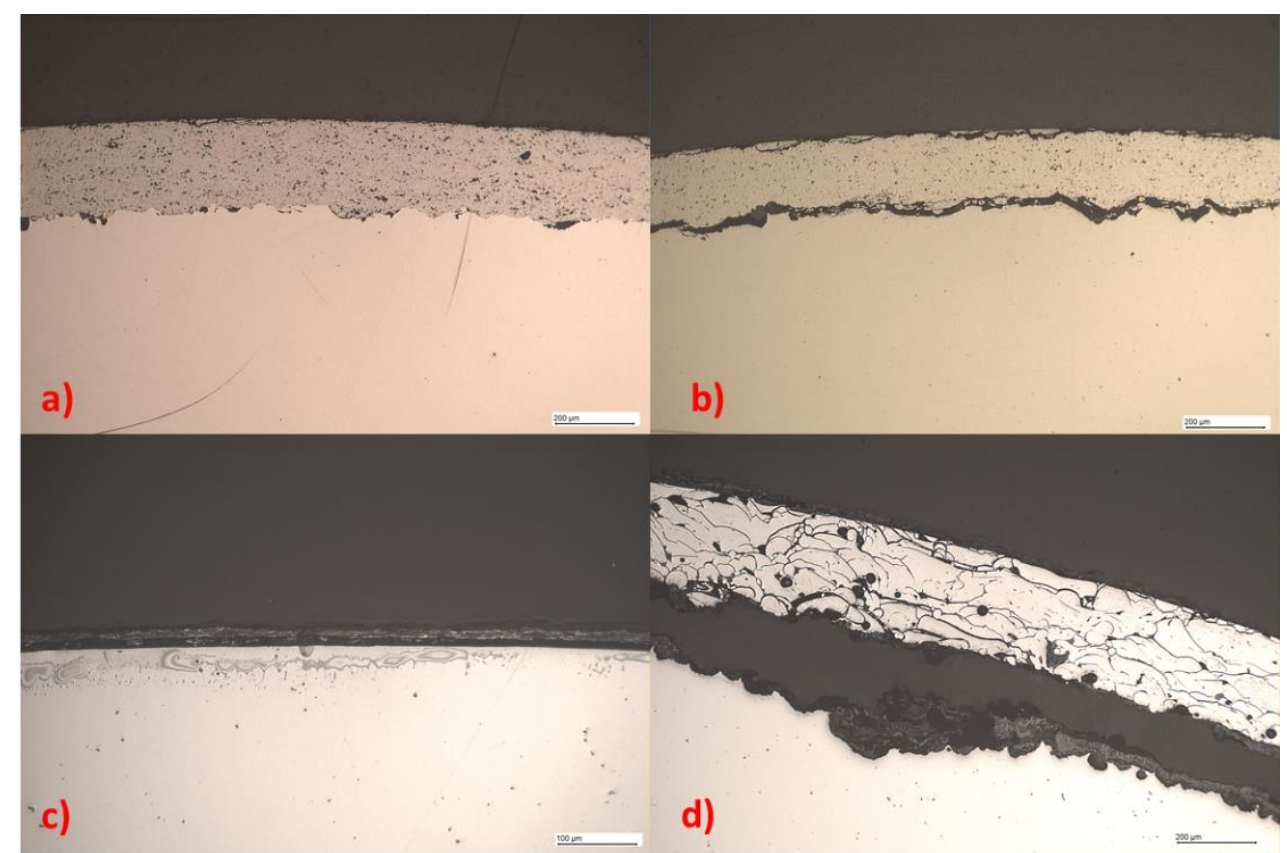

Figure 4 The microstructure of coatings after salt spray test: a) WC-CoCr (Woka 3652);

b) $\mathrm{CrC}-\mathrm{NiCr}$ (Amperit 588.074); c) Original coating - Geomet; d) NiCrBSi (FST 771.33)

\subsection{The component "Roll holder"}

For this component, the original part was also added to the test for comparison. The difference is that in this case, the original part is treated by paint coating on the whole surface except the functional areas stressed by friction. Contrary, the test thermally sprayed parts are treated only on the functional surface. The difference can be seen in (Figure 5), where the original part and the part sprayed by TWAS are shown. The corrosion of the original component is severe in the internal functional surfaces while on the exterior, the paint coating provides protection. The TWAS sprayed part is protected against corrosion in the internal functional surface, while the exterior is damaged. 


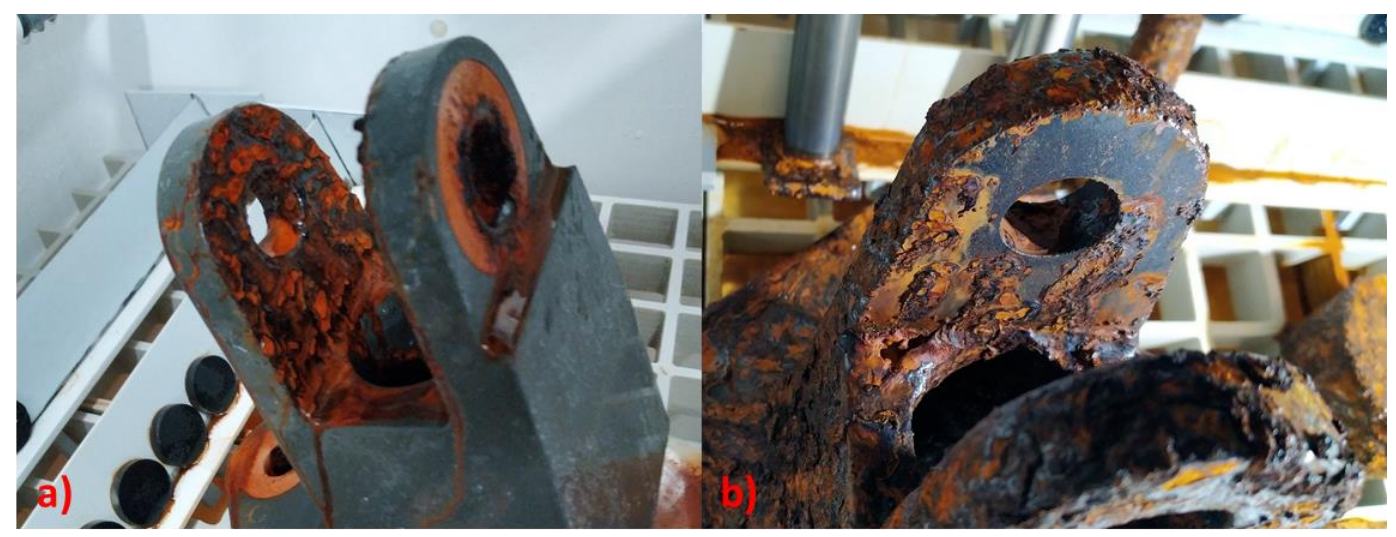

Figure 5 The tested parts "Roll holder" after $1000 \mathrm{~h}$ salt spray test.

a) original part b) TWAS sprayed Mo coating

The detailed behavior of the TWAS sprayed coatings is depicted on the cross-section in (Figure 6). Two sections of the component's surface are analyzed: The inner flat surface - sprayed in more standard incident angle; the internal diameter - sprayed in a more inclined angle where the coating can have lower quality. It is seen on cross-section, that the corrosion have affected the interface more severely at the internal diameter than in the case of the flat surface. From the used coatings, the CuAl shows better protection in salt spray conditions.

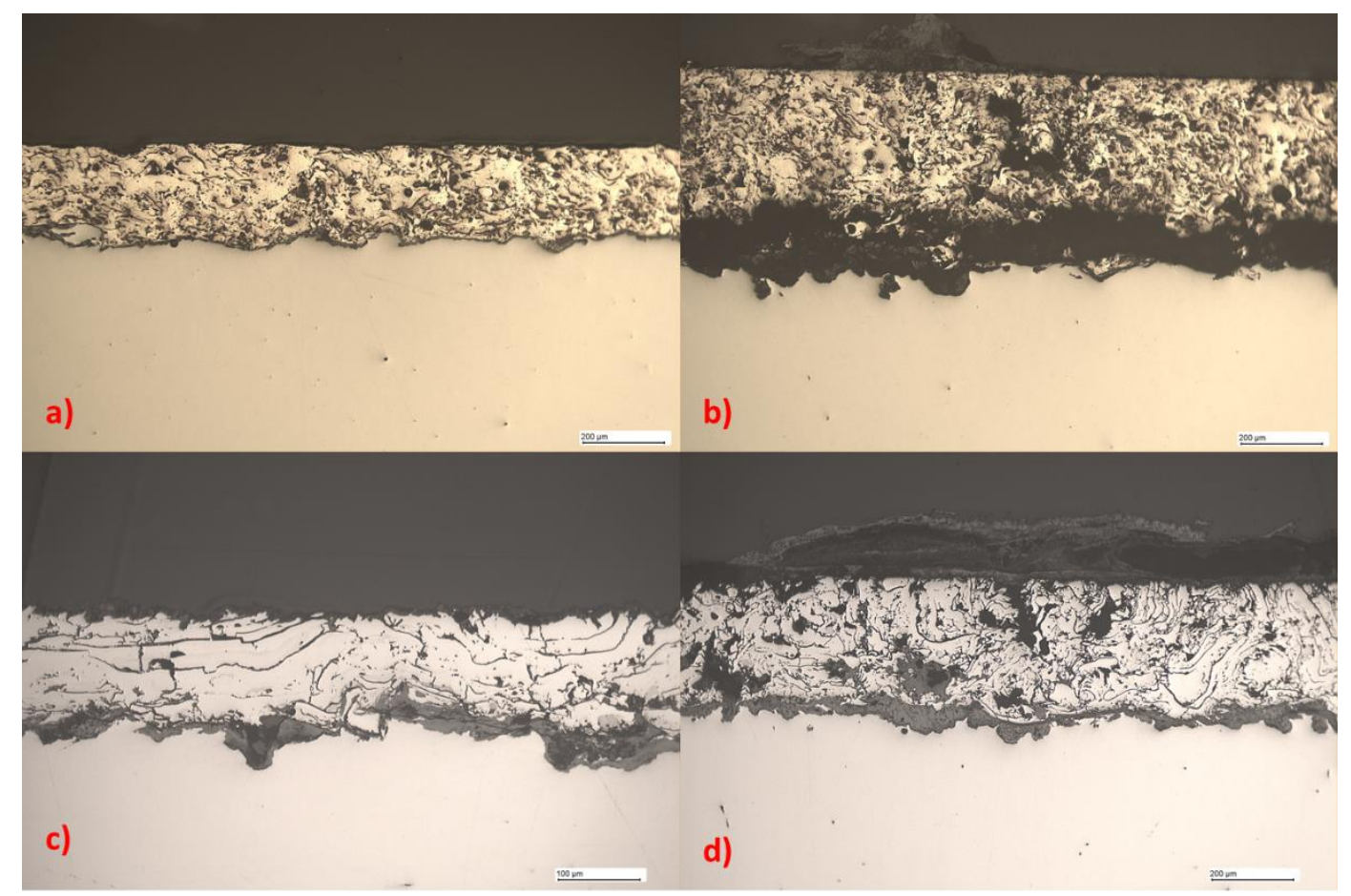

Figure 6 The microstructure of coatings after salt spray test: a) CuAl coating - flat surface b) CuAl - internal diameter c) Mo coating - flat surface d) Mo coating - internal diameter

\section{CONCLUSION}

The corrosion behavior in salt spray condition for $1000 \mathrm{~h}$ was tested for the two rail vehicles components treated using thermal sprayed coatings. The first component "Pivot" requires apart from high corrosion resistance also high hardness and wear resistance. The HVOF sprayed WC-CoCr coating shows the best 
performance from selected variants. The second component "Roll holder" requires apart from corrosion resistance suitable friction properties. The TWAS sprayed CuAl and Mo coatings were tested and the CuAl shows better behavior in salt spray. The additional analysis of corrosion product on the interface and detailed analysis of friction behavior will be conducted to correspondingly choose a more suitable coating for this component.

The thermal spraying is suggested only for functional surfaces of these pars, from technical reasons of the application process or the economical reasons. The original parts treated by conventional surface technologies such as chroming, Geomet, or paint system are usually treated on their whole surfaces. From this reason for best performance of the components would be crucial to develop a process of combination of these surface treatment technologies as well as to conduct a detailed analysis of the behavior on the interface between two applied surface treatment.

\section{ACKNOWLEDGEMENTS}

The paper has originated in the framework of the solution of project number FV40165 "Increasing of resistance of rail vehicles components by the means of modern thermal spraying technologies"

\section{REFERENCES}

[1] PAWLOWSKI, L. The Science and Engineering of Thermal Spray Coatings. Second edi. B.m.: John Wiley \& Sons, Ltd., 2008. ISBN 978-0-471-49049-4

[2] DAVIS, J. R. ASM Handbook, Volume 5A: Thermal Spray Technology. ASM International, 2004. ISBN: 978-161503-996-8.

[3] VARDELLE, A. M., MOREAU, Ch, VUORISTO, P, AKEDO, J. The 2016 Thermal Spray Roadmap. Journal of Thermal Spray Technology. [online]. 2016, vol. 25, pp. 1376-1440. Available from: https://doi.org/10.1007/s11666-016-0473-x.

[4] CARTIER, M. Handbook of surface treatments and coatings. American Society of Mechanical Engineers, January 1, 2003. ISBN: 978-1-86058-375-9.

[5] ŠULCOVÁ, P., VOSTŘÁK, M., ANTOŠ, J., LENCOVÁ, K. Improving Performance and Service Life of Rail Vehicles by Twin Wire Arc. In: Proceedings 29th International Conference on Metallurgy and Materials. [online]. 27th July 2020. ISBN: 978-80-87294-97-0. Available from: https://doi.org/10.37904/metal.2020.3570. 